\title{
PENGEMBANGAN MODEL MATEMATIKA JARINGAN SUPPLY CHAIN DENGAN MEMPERTIMBANGKAN EMISI PADA INDUSTRI DAUR ULANG KERTAS
}

\author{
Asgar Ali dan Nur Aini Masruroh \\ Program Studi Teknik Industri Fakultas Teknik \\ Universitas Gadjah Mada \\ Email: asgar456ali@gmail.com
}

\begin{abstract}
Recycling is part of the green supply chain management which is developed base on the concept of environmentally friendly industry to respond the various issues regarding the environmental problems of the world. Distribution of recycled products starts from consumers and ends to manufacturing. The objective is to limit the waste in order to save energy and prevent the dumping of hazardous materials into the environment. However there are complexities in the supply chain because of some uncertainties such as the return of recycled product and the environmental impact resulting from the operation of supply chain. In this research, linear programming optimization method is proposed to overcome that problem with maximizing profit is set as the objective function. Emissions resulting from the recycling process are considered in the model. These results indicate that the mathematical model provides profit of Rp. 37.909.659, with 1.137.760 grams of CO2 emissions from the production process, 38.473,4 grams of CO and 5.884,9 grams HC + NOX of transport. While the proposed strategy is use the right vehicles and select the most efficient route according to the paper collected from consumers and sold to manufacturing. For the production process, it is required to add 3 pressing machines and 1 chopped machine, so the capacity of the working hours of 384 hours per month can be increased to 960 hours per month.
\end{abstract}

Keyword: Environment; Linear Programming; Recycle; Uncertainty.

\begin{abstract}
ABSTRAK
Daur ulang merupakan bagian dari green supply chain management yang dikembangkan berdasarkan pada konsep industri berwawasan lingkungan dalam menjawab berbagai isu mengenai permasalahan lingkungan dunia. Distribusi produk daur ulang dimulai dari konsumen dan akhirnya sampai pada manufaktur. Tujuannya adalah agar dapat membatasi waste guna menghemat energi dan mencegah pembuangan bahan berbahaya ke lingkungan. Namun terdapat kompleksitas dalam supply chain daur ulang karena ketidakpastian seperti return product serta dampak lingkungan yang dihasilkan dari operasi supply chain. Pada penelitian ini, metode optimasi linear programming digunakan untuk mengatasi masalah memaksimalkan profit di dalam fungsi tujuan. Sedangkan emisi dari proses daur ulang berdasarkan hasil dari model. Hasil penelitian menunjukan model matematika menghasilkan profit sebesar Rp. 37.909.659, dengan emisi 1.137.760 gram $\mathrm{CO}_{2}$ dari proses produksi, 38.473,4 gram $\mathrm{CO}$ dan 5.884,9 gram $\mathrm{HC}+\mathrm{NO}_{x}$ dari transportasi. Sedangkan strategi yang diusulkan yaitu penggunaan kendaraan dengan rute yang efisien dengan mempertimbangkan kertas bekas yang dikumpulkan dari konsumen maupun yang dijual ke manufaktur. Untuk proses produksi, diperlukan penambahan 3 mesin press dan 1 mesin rajang, sehingga kapasitas jam kerja dari 384 jam per bulan dapat meningkat menjadi 960 jam per bulan.
\end{abstract}

Kata Kunci: Daur Ulang; Ketidakpastian; Linear Programming; Lingkungan. 


\section{PENGANTAR}

Isu mengenai permasalahan lingkungan dunia telah menjadi perhatian dari berbagai pihak, terutama beberapa sektor yang terus tumbuh dan menjadi penyumbang turunnya kualitas lingkungan dunia. Beberapa sektor tersebut adalah proses industri, transportasi, limbah, produk pertanian, power stations, penggunaan lahan dan biomass burning, fossil fuel, perumahan, dan lain-lain. Tumbuhnya sektor tersebut disebabkan karena adanya peningkatan aktivitas sosial ekonomi manusia untuk dapat memenuhi kebutuhan sehari-hari manusia. Namun, limbah yang dihasilkan dari sektor-sektor tersebut berdampak negatif terhadap lingkungan, sehingga dapat mengancam keberlangsungan hidup manusia.

Daur ulang adalah bagian dari konsep green supply chain management untuk mengikuti perkembangan konsep industri berwawasan lingkungan dalam menjawab isu mengenai permasalahan lingkungan dunia. Daur ulang merupakan salah satu cara untuk mengubah efek limbah yang negatif menjadi bahan baku untuk beberapa produk yang memiliki nilai fungsional yang positif dan menjadi sesuatu yang berguna bagi masyarakat (Srivastava, 2007; Ninlawan $\mathrm{dkk}, 2010)$. Hal ini dikarenakan daur ulang dapat memperpanjang penggunaan produk yang telah habis digunakan oleh konsumen sehingga dapat mengurangi limbah yang dibuang dan dapat meminimalkan penggunaan bahan baku yang baru untuk membuat produk baru.

Alur supply chain dari proses daur ulang produk bekas dilakukan secara terbalik (reverse supply chain), yaitu dimulai dari konsumen dan pada akhirnya sampai pada manufaktur untuk diproduksi menjadi produk baru atau produk yang sama dan dapat digunakan kembali (Hickford \& Cherrett, 2007). Tujuannya adalah agar dapat membatasi waste guna menghemat energi dan mencegah pembuangan bahan berbahaya ke lingkungan.

Beberapa tahun terakhir, reverse supply chain menjadi salah satu topik penelitian yang menarik, khususnya dengan menambahkan gas emisi yang dihasilkan dari rantai pasok tersebut. Seperti yang dapat ditemukan dalam beberapa literatur antara lain Sheu (2008),
Chaabane, dkk (2012), serta Tsai dan Hung (2009). Akan tetapi, operasi reverse supply chain tersebut mempunyai tantangan yang menyebabkan terjadinya kompleksitas yaitu ketidakpastian return product menjadi lebih sulit karena tidak ada data (distribusi) yang pasti mengenai produk karena kecepatan pengembalian produk yang sulit diukur (Hickford \& Cherrett, 2007). Untuk itu, mengelola kompleksitas supply chain dapat menghasilkan kinerja rantai pasok yang lebih baik (Serdarasan, 2013).

Untuk itulah, penelitian ini bertujuan untuk membuat model matematika supply chain daur ulang kertas bekas yang optimal dan menghitung emisi yang dihasilkan dengan mempertimbangakan ketidakpastian return product, serta mengevaluasi setiap strategi yang dapat digunakan untuk menghadapi ketidakpastian tersebut.

Metode yang digunakan yaitu metode optimasi linear programming untuk model yang pertama. Metode optimasi ini dipilih karena karakteristiknya sesuai dengan permasalahan jaringan supply chain daur ulang kertas yang dihadapi. Linear programming menggunakan model matematika untuk menggambarkan suatu masalah yang meliputi perencanaan aktivitas untuk mendapatkan hasil yang terbaik (optimal) di antara semua kemungkinan alternatif yang mungkin terjadi (Hillier \& Lieberman, 2005). Sedangkan untuk model yang kedua akan dihitung berdasarkan output dari model yang pertama.

\section{HASIL DAN PEMBAHASAN \\ Gambaran Sistem}

Pada penelitian ini, yang menjadi objek utama dalam jaringan supply chain daur ulang kertas adalah UD. Sregep. Kertas bekas yang dikumpulkan perusahaan tersebut berasal dari berbagai konsumen yang ada di wilayah Yogyakarta. Dimana terdapat jenis-jenis kertas bekas yang dikumpulkan yaitu HVS, Koran, Arsip, Art Paper, Ivory, Marga, dan Mix/As.

Kertas-kertas bekas tersebut kemudian akan melalui proses produksi yaitu proses sorting, rajang, serta press. Proses sorting dilakukan untuk memisahkan kertas berdasar- 
kan kondisinya yaitu kondisi kertas bekas yang baik dan tidak baik. Kertas dengan kondisi yang tidak baik juga dipisahkan antara yang masih dapat dijual dengan yang tidak mempunyai nilai jual, maka harus dibuang.

Pada proses rajang, kertas bekas akan dipotong-potong menjadi kertas dalam ukuranukuran yang kecil dengan menggunakan mesin rajang. Kemudian berlanjut pada proses press kertas bekas menjadi bentuk- bentuk persegi dengan berat yang sama yaitu 1 kilogram. Kertas bekas yang telah diproses tersebut, kemudian dijual atau dikirimkan ke manufaktur yang memproduksi produk kertas baru. Diketahui pula bahwa berapapun jumlah kertas bekas yang diproses oleh UD. Sregep akan terserap oleh manufaktur.

Secara jelas, gambaran tentang jaringan supply chain daur ulang kertas UD. Sregep dapat dilihat pada Gambar 1.

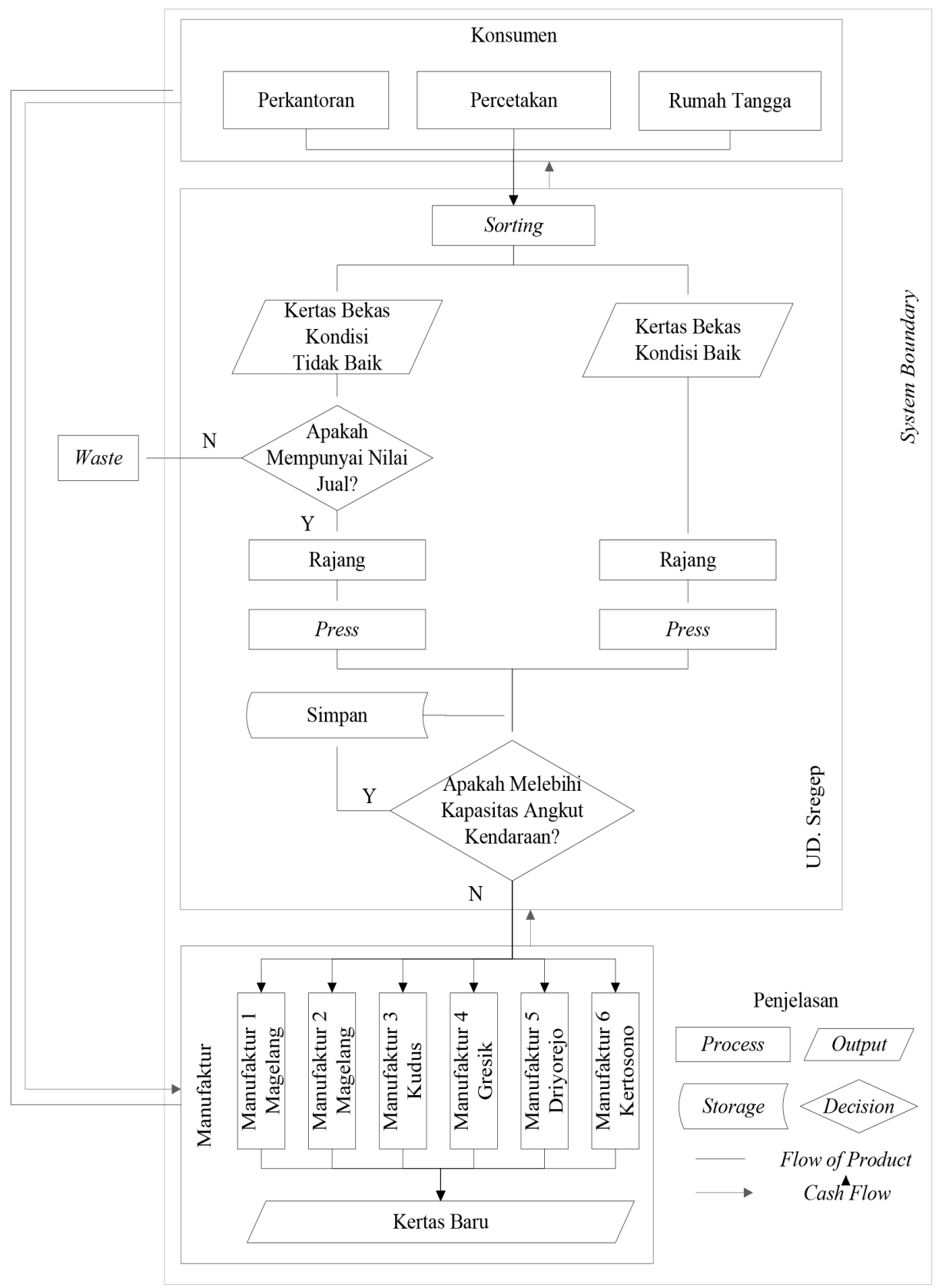

Gambar 1.

Jaringan Supply Chain Daur Ulang Kertas UD. Sregep 


\section{Formulasi Model}

Notasi dari indeks, parameter dan variabel yang digunakan dalam membuat model matematika Linear Programming jaringan supply chain daur ulang kertas sebagai berikut:

\section{Indeks Model}

$i \quad$ Jenis kertas bekas $(i=1,2,3, \ldots ., o)$

$j \quad$ Konsumen $(j=1,2,3, \ldots . ., z)$

$k \quad$ Manufaktur $(k=1,2,3, \ldots ., v)$

$l \quad$ Kondisi kertas bekas (l=baik, tidak baik)

$m \quad$ Jenis kendaraan $(m=$ truk ringan, truk sedang, truk berat)

$n \quad$ Jenis emisi gas buang $\left(n=\mathrm{CO}, \mathrm{CO}_{2^{\prime}}\right.$ $\mathrm{HC}+\mathrm{NO}_{x}$ )

$w \quad$ Jenis periode waktu $(w=1,2,3, \ldots ., u)$

\section{Parameter Model}

Pi Biaya proses produksi kertas bekas $i$ (Rp/kg)

$f \quad$ Biaya tenaga kerja $(\mathrm{Rp} /$ bulan/tenaga kerja)

$b_{j m}{ }^{\text {trans }}$ Biaya transportasi pengumpulan kertas bekas dari konsumen $j$ dengan kendaraan $m(\mathrm{Rp} / \mathrm{kg})$

$b_{k m}$ trans Biaya transportasi pengiriman kertas bekas ke manufaktur $k$ dengan kendaraan $m(\mathrm{Rp} / \mathrm{kg})$

$h \quad$ Biaya handling per kertas bekas di gudang (Rp/kg)

$h^{\text {maks }}$ Biaya handling maksimal yang telah ditetapkan (Rp)

$b_{i j}$ beli Harga beli kertas bekas dari konsumen ( $\mathrm{Rp} / \mathrm{kg})$

$b_{i l}$ jual Harga jual kertas bekas $i$ dalam kondisi yang telah diproduksi ( $\mathrm{Rp} / \mathrm{kg})$

$g \quad$ Jumlah tenaga kerja (orang)

$c^{\text {prod }}$ Kapasitas waktu produksi kertas bekas yang tersedia (jam)

$c_{m}{ }^{k n d r}$ Kapasitas angkut kendaraan $m(\mathrm{~kg})$

$c^{i v t y} \quad$ Kapasitas gudang penyimpanan $(\mathrm{kg})$

$t_{i}{ }^{\text {prod }}$ Waktu proses sorting, rajang, dan press kertas bekas $i$ (jam $/ \mathrm{kg}$ )

$d_{i j}{ }^{\text {Prsh }}$ Permintaan kertas bekas $i$ oleh perusahaan dari konsumen $j(\mathrm{~kg})$

$d_{i k l}{ }^{m f k r}$ Permintaan kertas bekas $i$ dalam kondisi oleh manufaktur $k(\mathrm{~kg})$ $s_{i=w} \quad$ Sisa kertas bekas $i$ yang belum diproduksi pada periode ke $w(\mathrm{~kg})$

$\lambda j$ Jarak antara perusahaan dengan konsumen $j(\mathrm{~km})$

$\mu k$ Jarak antara perusahaan dengan manufaktur $k(\mathrm{~km})$

$e_{n}^{\text {prod }}$ Nilai ambang batas maksimal emisi gas buang $n$ yang dihasilkan dari proses produksi kertas bekas (gram/ bulan)

$e_{\text {mпг }}$ Nilai ambang batas maksimal emisi gas buang $n$ yang dihasilkan oleh kendaraan $m$ setiap periode $w$ (gram/ bulan)

Variabel

$X_{\text {irw }} \quad$ Jumlah produk bekas $i$ dalam kondisi $l$ yang diproduksi pada periode $w(\mathrm{~kg})$

$\delta_{i j w} \quad$ Jumlah produk bekas $i$ yang dibeli dari konsumen $j$ pada periode $w(\mathrm{~kg})$

$\theta_{i k l} \quad$ Jumlah produk bekas $i$ yang sudah diproduksi dalam kondisi $l$ dijual ke manufaktur $k(\mathrm{~kg})$

\section{Variabel Dependent}

$e_{i l n}$ prod Emisi gas $n$ buang yang dihasilkan dari proses produksi kertas bekas $i$ dalam kondisi $l$ (gram/kg)

$e^{1}{ }_{m n} \quad$ Emisigas buang $n$ yang dihasilkan oleh kendaraan $m$ untuk mengumpulkan kertas bekas dari konsumen (gram/ $\mathrm{km}$ )

$e^{2}{ }_{m n} \quad$ Emisi gas buang yang dihasilkan oleh kendaraan $m$ untuk mengirimkan kertas bekas ke manufaktur (gram/ $\mathrm{km})$

\section{Model Pertama: Memaksimumkan Total Profit}

Formulasi matamatika pada persamaan (1) merupakan fungsi tujuan yang berkaitan dengan proses yang terjadi pada jaringan supply chain daur ulang kertas untuk mencapai keuntungan yang semaksimal mungkin. Profit yang diterima setiap periodenya didapat dari selisih antara pendapatan dengan total biaya produksi dan transportasi kertas bekas. 
Max Total Profit per Periode $=$

$$
\begin{aligned}
& \sum_{i} \sum_{k} \sum_{l} b_{i l}^{\text {jual }} \theta_{i k l}-\sum_{i} \sum_{l} p_{i} \chi_{i l w}-\sum_{i} \sum_{j} b_{i j}^{\text {beli }} \delta_{i j w} \\
& -\sum_{i} \sum_{k} \sum_{l} h\left(s_{i w}+\left(\chi_{i l w}+\chi_{i l w-1}-\theta_{i k l}\right)\right)-f \\
& -\sum_{i} \sum_{l} b_{j m}^{\text {trans }} \delta_{i j w}-\sum_{i} \sum_{k} \sum_{l} b_{k m}^{\text {trans }} \theta_{i k l}
\end{aligned}
$$

Persamaan (2) merupakan batasan model yang berkaitan dengan total biaya handling seluruh kertas bekas yang disimpan di gudang penyimpanan. Persamaan (3) merupakan waktu proses produksi yang terdiri dari proses sorting, rajang dan press. Persamaan (4) dan persamaan (5) berkaitan dengan kapasitas angkut kendaraan yang digunakan untuk mengumpulkan atau membeli kertas bekas dari kosumen dan untuk mengirimkan kertas bekas yang telah melalui proses sorting, rajang, dan press ke manufaktur. Persamaan (6) berkaitan dengan kapasitas maksimal kertas bekas yang dapat ditangani di gudang penyimpanan. Persamaan (7) berkaitan dengan jumlah masing-masing kertas bekas yang melalui proses produksi. Sedangkan persamaan (8) menunjukan jumlah masing-masing kertas bekas yang dijual ke manufaktur.

$$
\sum_{i} \sum_{k} \sum_{l} h\left(s_{i w}+\left(\chi_{i l w}+\chi_{i l w-1}-\theta_{i k l}\right)\right) \leq h^{\text {maks }}
$$$$
\sum_{i} t_{i}^{\text {prod }} \leq c^{\text {Prod }}
$$

$$
\sum_{i} \sum_{j} \delta_{i j w} \leq c_{m}^{k n d r}
$$

$$
\sum_{i} \sum_{k} \sum_{l} \theta_{i k l} \leq c_{m}^{k n d r}
$$

$$
\sum_{i} \sum_{k} \sum_{l}\left(s_{i w}+\left(\chi_{i l w}+\chi_{i l w-1}-\theta_{i k l}\right)\right) \leq c^{i v t y}
$$

$$
\begin{aligned}
& \sum_{l} \chi_{i l w} \leq \sum_{j}\left(\delta_{i j w}+s_{i w-1}\right) \quad \forall i \\
& \sum_{k} \sum_{l} \theta_{i k l} \leq \sum_{l}\left(\chi_{i l w}+\chi_{i l w-1}\right) \quad \forall i
\end{aligned}
$$

Batasan yang terkait dengan permintaan kertas bekas dapat dilihat pada persamaan (9) yang berarti berapapun kertas bekas yang ada di masing-masing konsumen akan terserap oleh perusahaan. Selain itu, terdapat juga persamaan (10) berarti berapapun produk bekas yang sudah diproduksi oleh perusahaan akan terserap oleh manufaktur.

$$
\begin{array}{ll}
\sum_{i} \delta_{i j w} \geq \sum_{i} d_{i j}^{p r s h} & \forall j \\
\sum_{i} \theta_{i k l} \geq \sum_{i} d_{i k l}^{m f k r} & \forall k, l
\end{array}
$$

\section{Model Kedua: Total Emisi Gas Buang}

Model kedua yaitu menghitung emisi gas buang yang merupakan efek samping dari proses yang terjadi pada jaringan supply chain daur ulang kertas. Secara lengkap formulasi matematika dari fungsi tujuan tersebut dapat dilihat pada persamaan (11).

$$
\begin{aligned}
& \text { Emisi Gas Buang }= \\
& \sum_{i} \sum_{l} \sum_{n} \chi_{i l w} e_{i l n}^{\text {prod }}+\sum_{j} \sum_{k} \sum_{m} \sum_{n}\left(e_{m n}^{1} \lambda_{j}+e_{m n}^{2} \mu_{k}\right) \text { (11) }
\end{aligned}
$$

Model tersebut tersebut mempunyai batasan yang berkaitan dengan nilai ambang batas emisi gas buang yang diperbolehkan. Pada persamaan (12) yaitu batasan yang berkaitan dengan nilai ambang batas emisi gas buang dalam proses produksi kertas daur ulang. Sedangkan persamaan (13) berkaitan dengan nilai ambang batas emisi gas buang yang dihasilkan oleh kendaraan yang digunakan oleh jaringan supply chain daur ulang kertas.

$$
\begin{aligned}
& \sum_{i} \sum_{l} \sum_{n} \chi_{i l w} e_{i l n}^{\text {prod }} \leq e l_{n}^{\text {prod }} \\
& \sum_{j} \sum_{k} \sum_{m} \sum_{n}\left(e_{m n}^{1} \lambda_{j}+e_{m n}^{2} \mu_{k}\right) \leq e l_{m n w}
\end{aligned}
$$




\section{Solusi Model}

Solusi optimal dari model didapatkan dengan menggunakan solver di dalam softwere Microsoft Excel.

Jaringan supply chain daur ulang kertas yang dimulai dari proses pengumpulan kertas bekas yang ada di konsumen dengan menggunakan 5 kendaraan jenis truk kecil dengan kapasitas angkut per bulan yaitu $60.000 \mathrm{~kg}$.

Tabel 1

Kertas Bekas yang Dikumpulkan dari Masing-Masing Konsumen

\begin{tabular}{l|l|l|l}
\hline \multicolumn{1}{c|}{ Jenis Kertas Bekas } & \multicolumn{1}{|c|}{ Perkantoran $(\mathrm{Kg})$} & Percetakan $\mathbf{( K g )}$ & Rumah Tangga $(\mathrm{Kg})$ \\
\hline HVS & 3295 & 0 & 0 \\
\hline Koran & 0 & 3799 & 0 \\
\hline Arsip & 20985 & 0 & 0 \\
\hline Arr Paper & 523 & 0 & 0 \\
\hline Ivory & 1355 & 0 & 0 \\
\hline Marga & 0 & 0 & 813 \\
\hline Mix/As & 0 & 0 & 12512 \\
\hline
\end{tabular}

Tabel 1 menunjukan kertas bekas yang dikumpulkan dari konsumen, yang jumlah secara keseluruhannya adalah 43.282 $\mathrm{kg}$, dengan biaya transportasi sebesar Rp1.298.460,00 serta biaya untuk membeli kertas bekas tersebut adalah sebesar Rp 103.749.700,00

Proses produksi kertas bekas yang terdiri dari proses sorting, rajang dan press mempunyai kapasitas waktu produksi adalah 384 jam per bulan. Dengan menggunakan seluruh waktu yang tersedia, jumlah kertas bekas yang melalui proses produksi adalah $14.222 \mathrm{~kg}$ dari $43.282 \mathrm{~kg}$ kertas bekas yang tersedia. Untuk selengkapnya dapat dilihat pada tabel 2.

Sedangkan terdapat $17 \mathrm{~kg}$ kertas bekas dalam kondisi tidak baik yang memang tidak mempunyai nilai jual sehingga harus dibuang. Oleh karena itu, jumlah kertas bekas yang melalui proses produksi mengalami penyusutan menjadi $14.205 \mathrm{~kg}$. Dengan biaya produksi sebesar Rp200,00 per kg, maka total biaya produksi yang dibutuhkan adalah sebesar Rp2.844.444,00

Tabel 2

Kertas Bekas yang Telah Melalui Proses Produksi

\begin{tabular}{l|l|l}
\hline \multicolumn{1}{c|}{ Jenis Kertas Bekas } & \multicolumn{1}{|c|}{ Kondisi Baik (Kg) } & \multicolumn{1}{c}{ Kondisi Tidak Baik (Kg) } \\
\hline HVS & 3295 & 0 \\
\hline Koran & 3799 & 0 \\
\hline Arsip & 3302 & 3286 \\
\hline Art Paper & 523 & 0 \\
\hline Ivory & 0 & 0 \\
\hline Marga & 0 & 0 \\
\hline Mix/As & 0 & 0 \\
\hline
\end{tabular}

Kertas bekas yang telah diproduksi, kemudian dikumpulkan bersama dengan kertas bekas yang telah melalui proses produksi pada periode sebelumnya dan dikirimkan ke manufaktur.
Melalui skenario pertama yaitu dengan menggunakan kapasitas angkut kendaraan $60.000 \mathrm{~kg}$ per bulan, hasilnya dapat dilihat pada tabel 3 dan tabel 4 . Sedangkan untuk skenario kedua yaitu dengan menggunakan 
kapasitas angkut kendaraan $90.000 \mathrm{~kg}$ per bulan, hasilnya dapat dilihat pada tabel 5 dan tabel 6. Perbedaan tersebut dikarenakan UD. Sregep pada kondisi aktual hanya menggunakan kapasitas angkut kendaraan $60.000 \mathrm{~kg}$ per bulan, namun pada nyatanya kapasitas kendaraan dapat mencapai 90.000 $\mathrm{kg}$ per bulan.

Tabel 3

Kertas Bekas Kondisi Baik yang Dikirimkan ke Manufaktur dengan Kapasitas Kendaraan $60.000 \mathrm{~kg}$ perbulan

\begin{tabular}{l|l|l|l|l|l|l}
\hline $\begin{array}{c}\text { Jenis Kertas } \\
\text { Bekas }\end{array}$ & $\begin{array}{c}\text { Manufaktur } \\
\mathbf{1}(\mathbf{K g})\end{array}$ & $\begin{array}{l}\text { Manufaktur } \\
\mathbf{2}(\mathbf{K g})\end{array}$ & $\begin{array}{l}\text { Manufaktur } \\
\mathbf{3}(\mathbf{K g})\end{array}$ & $\begin{array}{l}\text { Manufaktur } \\
\mathbf{4}(\mathbf{K g})\end{array}$ & $\begin{array}{c}\text { Manufaktur } \\
\mathbf{5}(\mathbf{K g})\end{array}$ & $\begin{array}{c}\text { Manufaktur } \\
\mathbf{6}(\mathbf{K g})\end{array}$ \\
\hline HVS & 0 & 0 & 0 & 6952 & 343 & 0 \\
\hline Koran & 0 & 6952 & 0 & 0 & 6610 & 237 \\
\hline Arsip & 4635 & 0 & 6952 & 0 & 0 & 6715 \\
\hline Art Paper & 1023 & 0 & 0 & 0 & 0 & 0 \\
\hline Ivory & 300 & 0 & 0 & 0 & 0 & 0 \\
\hline Marga & 994 & 0 & 0 & 0 & 0 & 0 \\
\hline Mix/As & 0 & 0 & 0 & 0 & 0 & 0 \\
\hline
\end{tabular}

Tabel 4

Kertas Bekas Kondisi Tidak Baik yang Dikirimkan ke Manufaktur dengan Kapasitas Kendaraan $60.000 \mathrm{~kg}$ perbulan

\begin{tabular}{l|l|l|l|l|l|l}
\hline $\begin{array}{c}\text { Jenis Kertas } \\
\text { Bekas }\end{array}$ & $\begin{array}{l}\text { Manufaktur } \\
\mathbf{1}(\mathbf{K g})\end{array}$ & $\begin{array}{c}\text { Manufaktur } \\
\mathbf{2}(\mathbf{K g})\end{array}$ & $\begin{array}{l}\text { Manufaktur } \\
\mathbf{3}(\mathbf{K g})\end{array}$ & $\begin{array}{c}\text { Manufaktur } \\
\mathbf{4}(\mathbf{K g})\end{array}$ & $\begin{array}{c}\text { Manufaktur } \\
\mathbf{5}(\mathbf{K g})\end{array}$ & $\begin{array}{c}\text { Manufaktur } \\
\mathbf{6}(\mathbf{K g})\end{array}$ \\
\hline HVS & 0 & 0 & 0 & 0 & 0 & 0 \\
\hline Koran & 0 & 0 & 0 & 0 & 0 & 0 \\
\hline Arsip & 3048 & 3048 & 3048 & 3048 & 3048 & 3048 \\
\hline Art Paper & 0 & 0 & 0 & 0 & 0 & 0 \\
\hline Ivory & 0 & 0 & 0 & 0 & 0 & 0 \\
\hline Marga & 0 & 0 & 0 & 0 & 0 & 0 \\
\hline Mix/As & 0 & 0 & 0 & 0 & 0 & 0 \\
\hline
\end{tabular}

Tabel 5

Kertas Bekas Kondisi Baik yang Dikirimkan ke Manufaktur dengan Kapasitas Kendaraan $90.000 \mathrm{~kg}$ perbulan

\begin{tabular}{l|l|l|l|l|l|l}
\hline $\begin{array}{c}\text { Jenis Kertas } \\
\text { Bekas }\end{array}$ & $\begin{array}{c}\text { Manufaktur } \\
\mathbf{1}(\mathbf{K g})\end{array}$ & $\begin{array}{c}\text { Manufaktur } \\
\mathbf{2}(\mathbf{K g})\end{array}$ & $\begin{array}{l}\text { Manufaktur } \\
\mathbf{3}(\mathbf{K g})\end{array}$ & $\begin{array}{l}\text { Manufaktur } \\
\mathbf{4}(\mathbf{K g})\end{array}$ & $\begin{array}{c}\text { Manufaktur } \\
\mathbf{5}(\mathbf{K g})\end{array}$ & $\begin{array}{c}\text { Manufaktur } \\
\mathbf{6}(\mathbf{K g})\end{array}$ \\
\hline HVS & 0 & 0 & 0 & 1854 & 5441 & 0 \\
\hline Koran & 0 & 9620 & 0 & 0 & 4179 & 0 \\
\hline Arsip & 0 & 0 & 1940 & 7766 & 0 & 8597 \\
\hline Art Paper & 0 & 0 & 0 & 0 & 0 & 1023 \\
\hline Ivory & 0 & 0 & 300 & 0 & 0 & 0 \\
\hline Marga & 2620 & 0 & 7380 & 0 & 0 & 0 \\
\hline Mix/As & 7000 & 0 & 0 & 0 & 0 & 0 \\
\hline
\end{tabular}


Tabel 6

Kertas Bekas Kondisi Tidak Baik yang Dikirimkan ke Manufaktur dengan Kapasitas

Kendaraan $90.000 \mathrm{~kg}$ perbulan

\begin{tabular}{l|l|l|l|l|l|l}
\hline $\begin{array}{c}\text { Jenis Kertas } \\
\text { Bekas }\end{array}$ & $\begin{array}{l}\text { Manufaktur } \\
\mathbf{1}(\mathbf{K g})\end{array}$ & $\begin{array}{c}\text { Manufaktur } \\
\mathbf{2}(\mathbf{K g})\end{array}$ & $\begin{array}{l}\text { Manufaktur } \\
\mathbf{3}(\mathbf{K g})\end{array}$ & $\begin{array}{l}\text { Manufaktur } \\
\mathbf{4}(\mathbf{K g})\end{array}$ & $\begin{array}{c}\text { Manufaktur } \\
\mathbf{5}(\mathbf{K g})\end{array}$ & $\begin{array}{c}\text { Manufaktur } \\
\mathbf{6}(\mathbf{K g})\end{array}$ \\
\hline HVS & 0 & 0 & 0 & 0 & 0 & 0 \\
\hline Koran & 0 & 0 & 0 & 0 & 0 & 0 \\
\hline Arsip & 3048 & 3048 & 3048 & 3048 & 3048 & 3048 \\
\hline Art Paper & 0 & 0 & 0 & 0 & 0 & 0 \\
\hline Ivory & 0 & 0 & 0 & 0 & 0 & 0 \\
\hline Marga & 0 & 0 & 0 & 0 & 0 & 0 \\
\hline Mix/As & 0 & 0 & 0 & 0 & 0 & 0 \\
\hline
\end{tabular}

Untuk emisi gas buang yang dihasilkan dari operasi supply chain daur ulang kertas bekas, solusi optimalnya tergantung dari solusi optimal yang dihasilkan dari model yang pertama. Secara lengkap solusi optimal yang dihasilkan dan dibandingkan dengan kondisi aktual (real system) dapat dilihat pada tabel 7. Tujuan perbandingan ini adalah untuk mengetahui bahwa model yang dihasilkan lebih baik atau tidak.

Tabel 7

Perbandingan Kondisi Aktual dengan Model

\begin{tabular}{|c|c|c|c|}
\hline Deskripsi & Aktual & Skenario 1 & Skenario 2 \\
\hline Waktu proses produksi & 384 jam & 384 jam & 384 jam \\
\hline Kapasitas angkut truk ringan & $60.000 \mathrm{~kg}$ & $60.000 \mathrm{~kg}$ & $60.000 \mathrm{~kg}$ \\
\hline Kertas bekas yang dikumpulkan dari konsumen & $43.282 \mathrm{~kg}$ & $43.282 \mathrm{~kg}$ & $43.282 \mathrm{~kg}$ \\
\hline Biaya beli kertas bekas & Rp. 103.749 .700 & Rp. 103.749 .700 & Rp. 103.749 .700 \\
\hline Biaya transportasi pengumpulan kertas bekas & Rp. 1.305 .000 & Rp. 1.298.460 & Rp. 1.298 .460 \\
\hline Jumlah Kertas bekas yang diproduksi & $14.222 \mathrm{~kg}$ & $14.222 \mathrm{~kg}$ & $14.222 \mathrm{~kg}$ \\
\hline Biaya produksi & Rp. 2.844.444 & Rp. 2.844.444 & Rp. 2.844.444 \\
\hline Sisa kertas bekas yang belum diproduksi & $29.060 \mathrm{~kg}$ & $29.060 \mathrm{~kg}$ & $29.060 \mathrm{~kg}$ \\
\hline $\begin{array}{l}\text { Kertas bekas yang telah diproduksi pada } \\
\text { periode sebelumnya }\end{array}$ & $61.800 \mathrm{~kg}$ & $61.800 \mathrm{~kg}$ & $61.800 \mathrm{~kg}$ \\
\hline Kapasitas angkut truk berat & $60.000 \mathrm{~kg}$ & $60.000 \mathrm{~kg}$ & $90.000 \mathrm{~kg}$ \\
\hline Kertas bekas yang dijual & $60.000 \mathrm{~kg}$ & $60.000 \mathrm{~kg}$ & $76.006 \mathrm{~kg}$ \\
\hline Biaya transportasi pengiriman kertas bekas & Rp. 3.800 .000 & Rp. 3.800 .000 & Rp. 4.813 .695 \\
\hline Pendapatan & Rp. 209.737.460 & Rp. 209.737.460 & Rp. 245.850 .590 \\
\hline Kertas bekas yang disimpan di gudang & $45.065 \mathrm{~kg}$ & $45.065 \mathrm{~kg}$ & $29.060 \mathrm{~kg}$ \\
\hline Biaya handling & Rp. 135.196 & Rp. 135.196 & Rp. 87.179 \\
\hline Biaya tenaga kerja & Rp. 60.000 .000 & Rp. 60.000 .000 & Rp. 60.000 .000 \\
\hline $\mathrm{CO}_{2}$ dari proses produksi & 1.137.760 gram & 1.137.760 gram & 1.137.760 gram \\
\hline CO dari transportasi & $38.573,4$ gram & $38.473,4$ gram & 47.061,4 gram \\
\hline $\mathrm{HC}+\mathrm{NO}_{\mathrm{x}}$ dari transportasi & $5.914,9$ gram & $5.884,9$ gram & $6.883,7$ gram \\
\hline Profit & Rp. 37.903.120 & Rp. 37.909.659 & Rp. 73.057.112 \\
\hline
\end{tabular}




\section{Analisis Sensitivitas}

Analisis sensitivitas dilakukan dengan cara memasukan range nilai perubahan yang mungkin terjadi dari parameter model matematika menggunakan solver table pada softwere Microsoft Excel 2010, sehingga dapat diketahui nilai delta $(\Delta)$ atau nilai perubahan maksimal pada koefisien fungsi tujuan dan koefisien fungsi kendala agar solusi dari model tetap optimal.

Tabel 8

Perubahaan Koefisien Biaya Transportasi untuk Mengumpulkan Kertas Bekas dari Konsumen

\begin{tabular}{l|l|l|l}
\hline $\begin{array}{c}\text { Dari } \\
\text { Konsumen/Ke } \\
\text { UD Sregep (Rp) }\end{array}$ & $\begin{array}{c}\text { Perkan- } \\
\text { toran }\end{array}$ & $\begin{array}{c}\text { Per- } \\
\text { cetakan }\end{array}$ & $\begin{array}{c}\text { Rumah } \\
\text { Tangga }\end{array}$ \\
\hline HVS & $30(+1)$ & $30(-1)$ & $30(-1)$ \\
\hline Koran & $30(-1)$ & $30(+1)$ & $30(-1)$ \\
\hline Arsip & $30(+1)$ & $30(-1)$ & $30(-1)$ \\
\hline Art Paper & $30(+1)$ & $30(-1)$ & $30(-1)$ \\
\hline
\end{tabular}

\begin{tabular}{l|l|l|l}
\hline $\begin{array}{c}\text { Dari } \\
\text { Konsumen/Ke } \\
\text { UD Sregep (Rp) }\end{array}$ & $\begin{array}{c}\text { Perkan- } \\
\text { toran }\end{array}$ & $\begin{array}{c}\text { Per- } \\
\text { cetakan }\end{array}$ & $\begin{array}{c}\text { Rumah } \\
\text { Tangga }\end{array}$ \\
\hline Ivory & $30(+1)$ & $30(-1)$ & $30(-1)$ \\
\hline Marga & $30(-1)$ & $30(-1)$ & $30(+1)$ \\
\hline Mix/As & $30(-1)$ & $30(-1)$ & $30(+1)$ \\
\hline
\end{tabular}

Pada tabel 8, dapat dilihat bahwa keseluruhan biaya transportasi dari setiap kertas bekas akan mempengaruhi solusi optimal jika $=$ Rp 1. Selain biaya transportasi, terdapat harga beli masing-masing jenis kertas bekas dan jumlah kertas bekas yang dibeli, yang akan langsung mempengaruhi solusi optimal jika terjadi perubahan.

Berkaitan dengan proses produksi untuk mengolah kertas bekas yang telah dikumpulkan dari konsumen, terdapat dua koefisien yang berpengaruh terhadap fungsi tujuan yaitu waktu produksi yang dapat dilihat pada tabel 9 dan biaya produksi kertas bekas pada tabel 10 .

Tabel 9

Perubahaan Koefisien Waktu Produksi Kertas Bekas

\begin{tabular}{l|l|l|l|l|l|l|l}
\hline \multicolumn{1}{c|}{ Jenis Kertas } & \multicolumn{1}{c|}{ HVS } & Koran & Arsip & Art Paper & \multicolumn{1}{c|}{ Ivory } & Marga & Mix/As \\
\hline Waktu Produksi Awal (Jam/Kg) & 0,027 & 0,027 & 0,027 & 0,027 & 0,027 & 0,027 & 0,027 \\
\hline Batas Perubahan () (jam) & $+0,007$ & $+0,004$ & $\pm 0,001$ & $+0,001$ & $-0,006$ & $-0,008$ & $-0,009$ \\
\hline
\end{tabular}

Tabel 10

Perubahaan Koefisien Biaya Produksi Kertas Bekas

\begin{tabular}{l|l|l|l|l|l|l|l}
\hline \multicolumn{1}{c|}{ Jenis Kertas } & HVS & Koran & Arsip & Art Paper & Ivory & Marga & Mix/As \\
\hline $\begin{array}{l}\text { Biaya Produksi Awal } \\
(\mathrm{Rp} / \mathrm{Kg})\end{array}$ & 200 & 200 & 200 & 200 & 200 & 200 & 200 \\
\hline Batas Perubahan () (Rp) & +807 & +507 & +692 & +207 & - & - & - \\
\hline
\end{tabular}

Proses pengiriman kertas bekas yang telah diproduksi ke manufaktur, terdapat biaya transportasi dan harga jual masing-masing jenis kertas bekas yang mempengaruhi secara langsung solusi optimal yang dihasilkan. Perubahan tersebut dapat dilihat pada tabel 11 dan tabel 12.

Tabel 11

Perubahaan Koefisien Biaya Transportasi untuk Mengirimkan Kertas Bekas ke Manufaktur

\begin{tabular}{l|l|l|l|l|l|c}
\hline \multicolumn{1}{c|}{ Dari UD Sregep/Ke (Rp/Kg) } & Plant 1 & Plant 2 & Plant 3 & Plant 4 & Plant 5 & Plant 6 \\
\hline HVS & $50(-1)$ & $50(-1)$ & $60(-1)$ & $80( \pm 1)$ & $70( \pm 1)$ & $70(-1)$ \\
\hline Koran & $50(-1)$ & $50( \pm 1)$ & $60(-1)$ & $80(-1)$ & $70( \pm 1)$ & $70(-1)$ \\
\hline Arsip & $50(-1)$ & $50(-1)$ & $60( \pm 1)$ & $80( \pm 1)$ & $70(-1)$ & $70( \pm 1)$ \\
\hline
\end{tabular}




\begin{tabular}{l|l|l|l|l|l|l}
\hline \multicolumn{1}{c|}{ Dari UD Sregep/Ke (Rp/Kg) } & Plant 1 & Plant 2 & Plant 3 & Plant 4 & Plant 5 & Plant 6 \\
\hline Art Paper & $50(-1)$ & $50(-1)$ & $60(-1)$ & $80(-1)$ & $70(-1)$ & $70( \pm 1)$ \\
\hline Ivory & $50(-1)$ & $50(-1)$ & $60( \pm 1)$ & $80(-1)$ & $70(-1)$ & $70(-1)$ \\
\hline Marga & $50( \pm 1)$ & $50(-1)$ & $60( \pm 1)$ & $80(-1)$ & $70(-1)$ & $70(-1)$ \\
\hline Mix/As & $50( \pm 1)$ & $50(-1)$ & $60(-1)$ & $80(-1)$ & $70(-1)$ & $70(-1)$ \\
\hline
\end{tabular}

Tabel 12

Perubahaan Koefisien Harga Jual Kertas Bekas ke Manufaktur

\begin{tabular}{l|l|l}
\hline Dari UD Sregep/Ke (Rp/Kg) & Kertas Bekas Kondisi Baik & Kertas Bekas Kondisi Tidak Baik \\
\hline HVS & $4000(-200)$ & - \\
\hline Koran & $3800( \pm 300)$ & - \\
\hline Arsip & $3400(-100)$ & $3200(-1300,+400)$ \\
\hline Art Paper & $3500(+200)$ & - \\
\hline Ivory & $2600(-100,+600)$ & - \\
\hline Marga & $2300(-100,+900)$ & - \\
\hline Mix/As & $2200(-2100,+100)$ & $2200(-2200,+3600)$ \\
\hline
\end{tabular}

Di sisi lainnya, fungsi tujuan untuk meminimalkan emisi juga mempunyai koefisien yang dapat mempengaruhi jumlah emisi secara keseluruhan. Koefisien pertama yaitu koefisien emisi yang dihasilkan oleh proses transportasi menggunakan kendaraan. Akan tetapi, koefisien tersebut sangatlah tergantung pada jumlah produk yang dikumpulkan dari konsumen dan yang dikirimkan ke manufaktur.

Koefisien yang kedua adalah koefisien emisi yang dihasilkan oleh proses produksi menggunakan mesin rajang dan press. Nilai koefisien awalnya adalah 80 gram/kg kertas bekas yang diproduksi. Perubahan nilai koefisien tersebut sebesar 1 gram $/ \mathrm{kg}$ kertas bekas akan langsung mengubah nilai optimal.

Jumlah kertas bekas yang ada pada konsumen dapat berubah seiring berjalannya waktu. Sehingga jika terjadi peningkatan atau penurunan jumlah kertas bekas yang diikumpulkan dari konsumen sebanyak 1 kg kertas bekas maka akan mengubah solusi optimal yang telah diketahui.

Berkaitan dengan kapasitas angkut kendaraan yang digunakan untuk mengangkut kertas bekas yang telah dibeli dari kosumen. Dengan jumlah kendaraan yang dimiliki adalah sebanyak lima kendaraan dan kapasitas masing-masing kendaraan yaitu 1500 kg, maka sejumlah kendaraan tersebut dapat digunakan sesuai dengan jumlah kertas bekas yang dapat dikumpulkan tersebut.

Untuk kapasitas waktu produksi yang tersedia sangat dipengaruhi oleh jumlah mesin yang digunakan. Oleh karena itu, jika terjadi perubahan jumlah mesin maka akan mempengaruhi kapasitas waktu produksi yang tersedia dan solusi optimal. Lebih jelasnya dapat dilihat pada tabel 13.

Tabel 13

Perubahaan Jumlah mesin dan Kapasitas Waktu Produksi Terhadap Solusi Optimal

\begin{tabular}{l|l|l|l|l|l|l|l|l|l}
\hline \multirow{1}{*}{ Jumlah mesin } & \multicolumn{2}{|c|}{$\begin{array}{c}\text { Kapasitas } \\
\text { Waktu Kerja }\end{array}$} & HVS & Koran & Arsip & $\begin{array}{c}\text { Art } \\
\text { Paper }\end{array}$ & Ivory & Marga & Mix/As \\
\hline $\begin{array}{l}4 \text { mesin rajang dan 1 } \\
\text { mesin press }\end{array}$ & 192 & 3295 & 3799 & 0 & 17 & 0 & 0 & 0 \\
\hline $\begin{array}{l}4 \text { mesin rajang dan 2 } \\
\text { mesin press }\end{array}$ & 384 & 3295 & 3799 & 6605 & 523 & 0 & 0 & 0 \\
\hline
\end{tabular}


ASGAR ALI DAN NUR AINI MASRUROH * PENGEMBANGAN MODEL MATEMATIKA JARINGAN SUPPLY CHAIN DENGAN MEMPERTIMBANGKAN EMISI PADA INDUSTRI DAUR ULANG KERTAS

\begin{tabular}{l|l|l|l|l|l|l|l|l|l}
\hline \multirow{2}{*}{ Jumlah mesin } & \multicolumn{2}{|c|}{$\begin{array}{c}\text { Kapasitas } \\
\text { Waktu Kerja }\end{array}$} & HVS & Koran & Arsip & $\begin{array}{c}\text { Art } \\
\text { Paper }\end{array}$ & Ivory & Marga & Mix/As \\
\hline $\begin{array}{l}4 \text { mesin rajang dan 3 } \\
\text { mesin press }\end{array}$ & 576 & 3295 & 3799 & 13716 & 523 & 0 & 0 & 0 \\
\hline $\begin{array}{l}4 \text { mesin rajang dan 4 } \\
\text { mesin press }\end{array}$ & 768 & 3295 & 3799 & 20827 & 523 & 0 & 0 & 0 \\
\hline $\begin{array}{l}5 \text { mesin rajang dan 5 } \\
\text { mesin press }\end{array}$ & 960 & 3295 & 3799 & 20985 & 523 & 1355 & 0 & 0 \\
\hline $\begin{array}{l}6 \text { mesin rajang dan 6 } \\
\text { mesin press }\end{array}$ & 1152 & 3295 & 3799 & 20985 & 523 & 1355 & 0 & 0 \\
\hline
\end{tabular}

Kapasitas angkut kendaraan untuk mengirimkan kertas bekas yang telah melalui proses produksi ke manufaktur, dapat disesuaikan dengan jumlah kertas bekas yang dikumpulkan dan diproduksi tersebut. Kapasitas maksimal kertas bekas yang dapat ditangani di gudang penyimpanan, jika terjadi perubahan kapasitas gudang penyimpanan di bawah $29.060 \mathrm{~kg}$, maka kondisi tersebut akan menjadi tidak feasible. Sedangkan total biaya handling seluruh kertas bekas yang disimpan di gudang akan menjadi tidak feasible jika batas biaya handling berada di bawah Rp87.179,00.

Perubahan nilai emisi maksimal yang dikeluarkan oleh kendaraan dalam waktu satu bulan, dapat mempengaruhi solusi optimal dari meminimalkan emisi, jika penggunaan kendaraan maksimal untuk mengirimkan kertas bekas ke manufaktur berkurang menjadi hanya dua kali dari tiga kali pengiriman dalam waktu satu bulan.

\section{SIMPULAN}

Simpulan yang diperoleh berdasarkan hasil dan pembahasan serta tujuan dari penelitian ini sebagai berikut: Pertama, Model matematika linear programming optimal yang dihasilkan melalui skenario pertama yaitu profit sebesar Rp37.909.659 dengan emisi 1.137.760 gram $\mathrm{CO}_{2}$ dari proses produksi, 38.473,4 gram CO dan 5.884,9 gram $\mathrm{HC}+\mathrm{NO}_{x}$ dari transportasi. Sedangkan untuk skenario yang kedua dengan peningkatan kapasitas angkut pengiriman kertas bekas ke manufaktur dari $60.000 \mathrm{~kg}$ per bulan menjadi $90.000 \mathrm{~kg}$ per bulan, juga meningkatkan profit sebesar Rp73.057.112 dengan emisi 1.137.760 gram
$\mathrm{CO}_{2}$ dari proses produksi, 47.061,4 gram $\mathrm{CO}$ dan 6.883,7 gram $\mathrm{HC}+\mathrm{NO}_{x}$ dari transportasi.

Kedua, Terdapat beberapa strategi yang dapat diterapkan oleh perusahaan agar mendapatkan profit yang maksimal yaitu penggunaan kendaraan yang disesuaikan dengan rute yang paling minimal dan jumlah kertas bekas yang dikumpulkan dari konsumen maupun jumlah kertas bekas yang dikirimkan dan dijual ke manufaktur. Selain itu, diperlukan penambahan jumlah mesin press sebanyak tiga mesin dan mesin rajang sebanyak satu mesin secara bertahap, sehingga kapasitas jam kerja menjadi maksimal dari 384 jam per bulan dapat meningkat menjadi 960 jam perbulan, sehingga akan berdampak pada peningkatan profit yang diterima oleh UD. Sregep.

\section{DAFTAR PUSTAKA}

Chaabane, A., Ramudhin, A., and Paquet, M., 2012, "Design of Sustainable Supply Chains Under the Emission Trading Scheme", Journal of Production Economics, 135, 37-49.

Hickford, A.J., and Cherrett, T.J., 2007, Green Logistics: Developing Innovative and More Sustainable Approaches to Reverse Logistics and the Collection, Recycling and Disposal of Waste Products from Urban Centres, Transportation Research Group, University of Southampton.

Hillier and Lieberman, 2005, Introduction Operations Research $8^{\text {th }}$ Edition, Andi, Yogyakarta. 
Ninlawan, C., Seksan, P., Tossapol, K., and Pilada, W., 2010, "The Implementation of Green Supply Chain Management Practices in Electronics Industry", Proceeding of the International Multi Converence of Engineers and Computer Scientists, Vol 3.

Sheu, J.B., 2008, “Green Supply Chain Management, Reverse Logistics and Nuclear Power Generation", Journal of Transportation Research, 44, 19-46.
Srivastava, S.K., 2007, “Green Supply-Chain Management: A State-Of-The-Art Literature Review", International Journal of Management Reviews, 9, 5380 .

Tsai, W.H., and Hung, S.J., 2009, “Treatment and Recycling System Optimisation With Activity-Based Costing in Weee Reverse Logistics Management: An Environmental Supply Chain Perspective", International Journal of Production Research, 47, 5391-5420. 